David de Jesús Aníbal Guerra

Claudia Llinas Torres Nadin Madera Arias

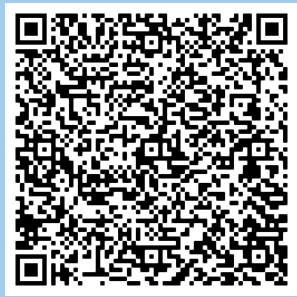




\title{
EL BIEN JURÍDICO TUTELADO EN LA PROHIBIGIÓN DEL DELITO DE TORTURA ${ }^{1}$
}

\author{
David de Jesús Aníbal Guerra², Claudia Llinas Torres ${ }^{3}$, Nadin Madera Arias ${ }^{4}$
}

\section{Palabras claves}

Derecho

penal, derecho

internacional, bien

jurídico, tortura,

Derechos Humanos

\section{Resumen}

El presente trabajo se deriva de la investigación jurídica denominada: El bien jurídico tutelado del delito de tortura en la perspectiva penal latinoamericana. La obra aborda el estudio del impacto jurídico que se genera en los eventos en que desde el derecho penal se establecen bienes jurídicos al delito de tortura que no son compatibles con los bienes jurídicos que se reconocen en el Derecho Internacional de los Derechos Humanos y que en dicha distorsión se puede generar la responsabilidad del Estado por su inobservancia al deber de adoptar disposiciones de derecho interno de conformidad con el mandato derivado de los tratados internacionales en materia de Derechos Humanos. Para el desarrollo de la temática se partió de una introducción a la temática para, luego, realizar un análisis de las normas y de la jurisprudencia internacional que se refieren a la tortura. Posteriormente, se abord la teoría del bien jurídico desde la perspectiva penal, para culminar con un examen detallado de los bienes jurídicos que en los distintos códigos penales de Latinoamérica se han establecido para proscribir la tortura. La metodología empleada para la investigación científica que originó este resultado de investigación, fue liderada bajo los lineamientos del paradigma hermenéutico en conjunto con el enfoque cualitativo y el método inductivo. El diseño o tradición de investigación empleado fue el de la teoría fundamentada y como técnicas de recolección de la información se emplearon la observación, el análisis de contenido y la entrevista.

1. Capítulo de libro derivado de investigación científica

2. Abogado egresado de la Universidad Simón Bolívar, Especialista en Derechos Humanos de la Escuela Superior de Administración Pública de Bogotá, Magister en Derechos Humanos de la Universidad de Alcalá, Doctor en Ciencias Políticas de la Universidad Rafael Belloso Chacín. Docente-Investigador Asociado y escritor. Abogado litigante. Correo: danibal@ unisimonbolivar.edu.co Orcid: https://orcid.org/0000-0002-1671-8469

3. Abogada egresada de la Universidad del Atlántico, Magíster en Derecho Administrativo de la Universidad Simón Bolívar Humanos de la Universidad de Alcalá, Candidata a Doctora en Ciencias de la Educación de la Universidad Simón Bolívar. Docente-Investigador Asociado y escritora. Abogada litigante. Email: cllinas5@unisimonbolivar.edu.co Orcid: https://orcid. org/0000-0002-2710-4358

4. Abogado egresado de la Universidad Simón Bolívar, Magíster en Derecho Constitucional de la Universidad Externado de Colombia. Docente-investigador y escritor. Abogado litigante. Email: nadin_madera@corposucre.edu.co Orcid: https:// orcid.org/0000-0002-1998-3284 


\section{Abstract}

Keywords

Criminal law, international law, legal good, torture, human rights
This work is derived from the legal investigation called: The legal good protected from the crime of torture in the Latin American criminal perspective. The work deals with the study of the legal impact that is generated in the events in which from the criminal law legal assets are established to the crime of torture that are not compatible with the legal assets that are recognized in International Human Rights Law and, which Such distortion may generate the State's responsibility for its failure to comply with the provisions of domestic law in accordance with the mandate derived from international human rights treaties. For the development of the theme, we will start by introducing the proposed theme and then perform an analysis of the norms and international jurisprudence that refer to torture. Subsequently, the theory of legal good will be approached from the criminal perspective, to culminate with a detailed examination of the legal assets that have been established in the various criminal codes of Latin America to outlaw torture. The methodology used for scientific research that originated this research result was led under the guidelines of the hermeneutical paradigm in conjunction with the qualitative approach and the inductive method. The research design or tradition used was that of grounded theory and as information collection techniques, observation, content analysis and interviewing were used. 


\section{INTRODUGGIÓN}

Uno de los mayores anhelos deseados por la humanidad, ha sido el reconocimiento de los Derechos Humanos como límite al actuar del Estado y su poder punitivo. Desde la conquista de los Derechos Humanos en la modernidad y, su apogeo en la edad contemporánea, estos se han mostrado como un escudo que impide que la intervención del Estado en la persona humana sea injustificada, desproporcional e inadmisible. Es decir, los Derechos Humanos han podido ser entendidos hoy en día, como el primer criterio de legitimidad de la actuación Estatal, cuestión esta que se ve reforzada por un derecho constitucional ligado a las bases de la dignidad humana, en el cual, no solo se busca que las actuaciones del Estado se produzcan dentro de un marco normativo, sino que, además, ese actuar no detrimente en manera alguna la dignidad del ser humano y, a la vez que, se vea al Estado como una construcción al servicio de las personas sujetas a su jurisdicción a través del deber de respectar y garantizar los derechos.

Es por lo anterior, que, dentro del deber de garantizar, los Estados deben determinarse a decidir sobre las medidas más convenientes para el libre y eficaz ejercicio de los Derechos Humanos y, para ello, deben tener en cuentas sus obligaciones internacionales y la manera en que estas inciden en el ordenamiento jurídico interno. De tal suerte que, la acción estatal no es ajena al derecho internacional. Ahora bien, como quiera que el objeto de estudio en este trabajo recae sobre la prohibición del delito de tortura se considera que dentro de las medidas tendientes a garantizar los Derechos Humanos, se deben disponer de medidas legislativas que se encuentren a tono con el efecto útil de cada figura de derecho y, que a su vez, la medida no sea incompatible con el derecho internacional, ya que de serlo, se puede llegar a comprometer la responsabilidad estatal en un caso de violación de Derechos Humanos por la indebida adecuación del ordenamiento jurídico interno al internacional a sabiendas de la vinculatoriedad del bloque de constitucionalidad y el control de convencionalidad.

En ese orden de ideas, al realizar un examen sobre los códigos penales de los países de la región en relación con la prohibición del delito de tortura, se observa una discusión en torno al bien jurídico tutelado que se protege al penalizar esta conducta, encontrándose como resultado que no existe un criterio uniforme para dicho asunto y, que el mismo, tampoco tiene en cuenta el bien jurídico que desde el derecho internacional de los Derechos Humanos se protege.

\section{Normas InternaGionales de}

\section{LA PROHIBICIÓN DEL DELITO DE}

\section{TORTURA, SENTIDO Y ALGANGE}

En materia de instrumentos de Derechos Humanos que prohíben la tortura y resultan aplicables sea por vía interpretativa, cuasi jurisdiccional o jurisdiccional, a los países que conforman la región latinoamericana, se pueden mencionar seis:

1. La Declaración Universal de Derechos Humanos de 1948,

2. El Pacto Internacional de Derechos Civiles y Político de 1966, 
3. La Convención Americana sobre Derechos Humanos de 1969,

4. La Declaración sobre la Protección de Todas las Personas contra la Tortura y otros Tratos o Penas Crueles, Inhumanos o Degradantes de 1975,

5. La Convención contra la Tortura y otros Tratos o Penas Crueles Inhumanos y Degradantes de 1984 y,

6. La Convención Interamericana para Prevenir y Sancionar la Tortura de 1985.

De estos seis instrumentos solo tres precisan que entender por el termino tortura. Estos son a saber: 1) La Declaración sobre la Protección de Todas las Personas contra la Tortura y otros Tratos o Penas Crueles, Inhumanos o Degradantes de 1975; 2) La Convención contra la Tortura y otros Tratos o Penas Crueles Inhumanos y Degradantes de 1984 y, 3) La Convención Interamericana para Prevenir y Sancionar la Tortura de 1985. Estos instrumentos, al definir la tortura lo hacen de manera similar a través de una serie de requisitos: Un primer requisito es el objetivo o material y, comprende, la realización de un acto o método, se aclara en este punto que, la Convención Interamericana para Prevenir y Sancionar la Tortura de 1985, también considera como tortura la aplicación de métodos tendientes a anular la personalidad de la víctima o a disminuir su capacidad física o mental, aunque no causen dolor físico o angustia psíquica. intencionado y destinado a producir penas, dolores o sufrimientos, sean físicos o mentales, importante mencionar que:

La Declaración sobre la Protección de Todas las Personas contra la Tortura y otros Tratos o Penas Crueles,
Inhumanos o Degradantes de 1975 y, la Convención contra la Tortura y otros Tratos o Penas Crueles Inhumanos y Degradantes de 1984, emplean la expresión penas, dolores o sufrimientos "Graves". Por su parte, la Convención Interamericana para Prevenir y Sancionar la Tortura de 1985, no emplea dicho termino, razón por la cual apoyado en el principio pro personae y en la doctrina iusinternacionalista, nos apoyaremos en la interpretación más benéfica que resulte a la prohibición de la tortura.

El segundo requisito es el teleológico. Es decir, la finalidad que se persigue con el empleo de la tortura sobre la persona, la cual a su vez puede ser:

1. Obtener una información o una confesión,

2. Castigar a una persona por un acto cometido o que se sospeche se ha cometido,

3. Intimidar o coaccionar a una persona o a otras,

4. Investigación criminal,

5. Servir como medio intimidatorio,

6. Servir como medida preventiva,

7. Cualquier razón basada en cualquier tipo de discriminación y,

8. Cualquier otro fin (Corte Interamericana de Derechos Humanos [Corte IDH], 2014a).

Un tercer elemento es el subjetivo, lo cual se traduce en que la tortura para efectos del Derecho Internacional de los Derechos Humanos, puede ser cometida por:

1. Un funcionario público, 
2. Cualquier persona en ejercicio de funciones públicas,

3. Particulares sometidos a instigación de funcionario público o, cualquier persona en ejercicio de funciones públicas y,

4. Particulares que cuenten con la aquiescencia de funcionario público o, cualquier persona en ejercicio de funciones públicas.

El cuarto requisito, la condición de vulnerabilidad de la víctima durante la duración de los procesos, empleado por algunos Tribunales Internacionales en materia de Derechos Humanos, permite tener en cuenta a la hora de estudiar un posible caso de tortura, una serie de factores como la edad (Tribunal Europeo de Derechos Humanos [TEDH], 2004a), el sexo (Corte IDH, 2006b), el estado psíquico y mental, el grado de escolaridad y la cosmovisión cultural de la víctima (Corte IDH, $2011 \mathrm{c}$ ), entre otros. Es de resaltarse, que estos requisitos son esenciales a la hora de determinar si una determinada violación de Derechos Humanos pertenece al grado de tortura o de otra conducta lesiva de la integridad personal. Ahora bien, estos requisitos no son limitables de las formas de tortura que puedan llegarse a producir en la actualidad, sino que, establecen un derrotero a través del cual se puede inferir razonadamente si se está en presencia de un caso de tortura o no (Corte IDH, 2016d).

Nótese que, la definición de tortura que, recogida por estos tres instrumentos, no categorizan puntualmente que acto específico puede considerarse por tortura y, que no debe entenderse o considerarse por ella. Ello ha sido una tarea que han desplegado, mayoritariamente, los órganos cuasi- jurisdiccionales y jurisdiccionales en materia de Derechos Humanos. Sin perjuicio de lo anterior, se puede afirmar que la tortura y las penas o tratos crueles, inhumanos o degradantes, se encuentran rigurosamente proscritos por el Derecho Internacional de los Derechos Humanos. La prohibición absoluta de la tortura, sea física o psicológica, pertenece al dominio del jus cogens internacional (Comité Contra la Tortura [CAT], 2008a; Corte IDH, 2015e). Cuestión que implica que, la alegada prohibición subsista aun en las circunstancias más difíciles dentro de un Estado, tales como: la guerra, la amenaza de guerra, la lucha contra el terrorismo y cualesquiera otras calamidades públicas (Corte IDH, 2006f; Corte IDH, 2015g).

En ese sentido, el Tribunal Europeo de Derechos Humanos (1978a; 2008b) ha establecido en casos como Ireland vs. United Kingdom y Chitayev \& Chitayev vs. Rusia que, atendiendo al Convenio Europeo de Derechos Humanos se prohíbe en términos absolutos la tortura y las penas o tratos inhumanos o degradantes, cualesquiera que sean los actos de la víctima. Por ende, no se establece ninguna excepción, ni se admite derogación ni aun en el caso de un peligro público que amenace a la vida de la nación o, circunstancias que configuren el crimen organizado a gran escala $(\mathrm{TEDH}$, 2000c; TEDH, 1999d; TEDH, 1996e; TEDH, 1992f). Bajo esos supuestos, la Corte Interamericana de Derechos Humanos también ha advertido que, la circunstancia de terrorismo por las cuales atraviese un Estado, no debe acarrear restricciones a la protección de la integridad física de la persona (Corte IDH, 1997h). Razón por la cual, cada Estado está en el deber de prevenir e investigar los 
actos de tortura cometidos bajo su jurisdicción (Corte IDH, 2016i).

Así las cosas, se puede puntualizar que en su posición de garante de los Derechos Humanos y, del correspondiente efecto vertical que de los mismos se predican, el Estado tiene la obligación primaria de evitar que en su jurisdicción se cometan actos de tortura sobre cualquier persona, so pena, de ser responsable por el hecho ilícito. Haciendo referencia a la naturaleza y sentido de la prohibición de la tortura, con especial atención a los instrumentos de Derechos Humanos que la proscriben y, de la jurisprudencia de los Tribunales Internacionales de Derechos Humanos, se puede precisar que, lo que se busca proteger con esta prohibición es prioritariamente el derecho a la integridad personal (Corte IDH, 2016j). En efecto, ello se desprende del análisis estructural y finalista sobre:

1. La Declaración Universal de Derechos Humanos de 1948,

2. El Pacto Internacional de Derechos Civiles y Políticos de 1966 y,

3. La Convención Americana sobre

Derechos Humanos de 1969;

De los cuales sus respectivos textos hacen alusión a la integridad personal, y no a otro bien jurídico diferente. Prueba de ello es que en sus Observaciones Generales No. 7 de 1982 y No. 20 de 1992, el Comité De Derechos Humanos de las Naciones Unidas, precisa que la finalidad de las disposiciones del artículo 7 del Pacto Internacional de Derechos Civiles y Políticos es: proteger la dignidad, la integridad física y mental de la persona; pronunciamiento este al que se le suman, los del Tribunal Europeo de Derechos Humanos (TEDH, 1995g), la Corte Interamericana de Derechos Humanos y, la Comisión Interamericana De Derechos Humanos (Comisión Interamericana De Derechos Humanos [CIDH], 2001a), en sus respetivos instrumentos, en el sentido que, la prohibición de la tortura asegura la integridad física, psíquica y moral de la persona, y prohíbe la injerencia arbitraria del Estado y de los particulares en esos atributos individuales (Corte IDH, 2011k).

En esa misma línea, el Comité Contra la Tortura ha sido del criterio que la finalidad que tiene la Convención contra la Tortura y otros Tratos o Penas Crueles Inhumanos y Degradantes es, sin duda alguna, la prohibición del flagelo de la tortura, pero que a su vez el bien jurídico tutelado con la prohibición de dicha práctica es la integridad personal del individuo (CAT, 2008b). Igualmente, se han pronunciados tribunales domésticos como es el caso de Corte Constitucional de Colombia (CCCO, 1992a), la cual en sentencia C-587 señala:

(...) La tortura es una de las muchas formas como se puede vulnerar el derecho a la integridad personal. Los tratos y las penas crueles, inhumanas o degradantes son, por ejemplo, otras formas de vulnerar ese derecho (...).

El mismo Tribunal (CGCO, 2002b) en sentencia C-1076 señaló que, la Convención Interamericana para Prevenir y Sancionar la Tortura se encaminaba a proteger un derecho humano intangible, como lo es la integridad física y, que a su vez, gozaba de un contenido más garantista que el de la Convención Contra la Tortura y otros Tratos o Penas Crueles Inhumanos o Degradantes (Pellet y Daillier, 1999; Díez de Velasco, 1999). 
Por otra parte, y, con el ánimo de puntualizar en el alcance de los casos que dan origen a la tortura, debe precisarse en un primer lugar que, actos que anteriormente eran considerados como tratos crueles, inhumanos o degradantes, han podido alcanzar el grado de tortura. Muestra de ello, es que la Comisión Interamericana de Derechos Humanos (1981b) en uno de sus informes sobre la situación de los Derechos Humanos en Colombia, detalló una lista de posibles conductas que pueden llegar a constituir tortura y, entre ellas se mencionan:

(...) plantones al sol en el día y al sereno en la noche; ahogamientos y sumergimientos en agua; aplicación del submarino; venda en los ojos hasta por doce, diez y siete y veinte días; vendado y amarrado por cuarenta y siete días en cimitarra; sometimiento a golpes en diversas partes del cuerpo con palos y patadas; impedimento para dormir hasta por ocho días y falta de reposo; apisapiamenazas de muerte al detenido, a la familia y a amigos; colgaduras atado de las manos; prohibición de agua y alimento hasta por cuatro, siete y ocho días seguidos; simulacro de dispararles en la cabeza; esposados de las manos; tortura de otras personas cerca de la celda para que se escucharan los gritos; incomunicación; palpitación de energía y choques eléctricos en diferentes partes del cuerpo; ejercicios hasta el agotamiento; permanencia desnudos y de pie; provocación de asfixia; lavadas; caminar de rodillas; torturas sicológicas; sumergimiento amarrados en un lago; quemaduras con cigarrillos; entre otras (...).
Seguidamente y, atendiendo a que según los tres instrumentos que definen la tortura, ésta puede comportar un sufrimiento psíquico o moral agudo sobre la víctima, se ha precisado que una forma de tortura sicológica es la mera amenaza de un peligro inminente sobre la vida o integridad de una persona. En concordancia con ello, amenazar a alguien con torturarle puede constituir, en determinadas circunstancias, por lo menos un trato inhumano (TEDH, 1982h). En esos términos, el Tribunal Europeo de Derechos Humanos, ha estimado que debe tomarse en cuenta, a efectos de determinar si se existe violación a la integridad personal, no sólo el sufrimiento físico, sino, también, la angustia moral (TEDH, 1989i), ya que aun en la ausencia de lesiones, los sufrimientos en el plano físico y moral, acompañados de turbaciones psíquicas, pueden ser considerados como tortura. El carácter degradante en esos eventos, se expresa en un sentimiento de miedo, ansia, inferioridad con el fin de humillar, degradar y de romper la resistencia física y moral de la víctima (TEDHa).

Por su parte, el Comité de Derechos Humanos de Naciones Unidas, calificó la amenaza de hacer sufrir a una persona una grave lesión física como una tortura psicológica (Comité de Derechos Humanos [CDH], 1983a), cuestión también avalada por la Corte Interamericana de Derechos Humanos (20111).

En cuanto al tema, el Comité Contra la Tortura de las Naciones Unidas (2007c), ha extendido el alcance de la prohibición de la tortura a otras conductas que anteriormente no se señalaban como tal, ejemplo de esto es el caso V.L vs. Suiza en el cual el 
comité señaló que la violación sexual hoy en día constituye un método moderno de tortura. Bajo esos mismos parámetros ya se habían tomado decisiones anteriormente en la esfera de algunos Tribunales Penales Internacionales, como es el caso de la Corte Penal Internacional para la Antigua Yugoslavia (ICTY, 2000) en el caso de Anto Furundzija, y el Tribunal Penal Internacional para Ruanda (ICGR, 1994) en el caso de Jean Paul Akayesu. El atraso en adoptar este delito como nuevo método de tortura, se dio por el carácter prematuro de estos tribunales penales internacionales que optaron por tomar dicha consideración atendiendo en que en sus respectivos estatutos la violación sexual es un crimen de lesa humanidad.

A raíz de lo anterior, otros organismos internacionales han adoptado esta postura, de entre los cuales se resaltan el Tribunal Europeo de Derechos Humanos (2004a) en el caso M.G vs. Bulgaria; la Comisión Interamericana de Derechos Humanos en el caso de Ana, Beatriz y Cecilia Gonzales Pérez vs. México (2001a) y, la Corte Interamericana De Derechos Humanos (2006b; 2011c; 2016d) en los casos del Penal Miguel Castro Castro Vs Perú, Rosendo Cantú vs México y Espinoza Gonzales vs Perú, afirmando que, la violación sexual constituye una afectación a la integridad física, psíquica y moral de la víctima, toda vez que es realizada dolosamente y sin su consentimiento. Cuestión última que produce un sufrimiento físico y mental a la víctima (Corte IDH, 2004m; Corte IDH, 2004n; Corte IDH, 2003o) que perdura en el tiempo ocasionando un trauma psicológico que resulta, del hecho de ser humillada y victimizada (CIDH, 2001a). Por ello, se ha entendido que la violación sexual es una experiencia sumamente traumática que puede tener severas consecuencias (Comisión de Derechos Humanos [CDDHH], 1995) y deja a la víctima humillada física y emocionalmente (TEDH, 1997j). En ese sentido el Relator Especial de las Naciones Unidas contra la Tortura ha señalado que la violación sexual es uno de los métodos de tortura física, utilizada en algunos casos para castigar, intimidar y humillar. Por todo lo anterior, puede concluirse que se ha conformado un verdadero régimen jurídico internacional de prohibición absoluta de todas las formas de tortura que, abarcan un abanico de nuevas conductas en busca de proteger la integridad personal del individuo y combatir la impunidad en estos casos.

\section{TeOría deL BIEN JURÍdico DeSDE LA PERSPEGTIVA PENAL}

El derecho penal puede ser comprendido como aquella parte del Derecho que se encarga de estudiar las conductas constitutivas de delitos y las sanciones que a estas se les puedan endilgar en calidad de pena. En el entendido de Jiménez de Asúa, el derecho penal es el conjunto de normas y disposiciones jurídicas que regulan el ejercicio del poder sancionador y preventivo del Estado, estableciendo el concepto de delito como presupuesto de la acción estatal, así como la responsabilidad del sujeto activo, y asociando a la infracción de la norma una pena finalista o una medida aseguradora (Jiménez, 1950).

Por su parte, Cervini (2016) considera que el derecho penal es el que se ocupa de estudiar el conjunto de infracciones que afectan gravemente el orden social sin una razón en derecho y, que, por tal cuestión, son merecedoras de sanción. En ese mismo 
sentido, Sánchez (2016) es del criterio que el derecho penal es el sector del ordenamiento jurídico o el conjunto de normas jurídicas que define delitos y faltas y prevé o asocia como consecuencia de la comisión de dichos delitos o faltas la imposición de penas y otras consecuencias penales o se trata del sector del ordenamiento jurídico que contiene las reglas jurídicas relativas a las infracciones penales y sus correspondientes consecuencias jurídicas. Requena y Díaz (2015) afirman que el objeto de estudio del derecho penal lo constituyen los hechos y omisiones que la ley reprocha y los considera como delitos.

Lo cierto es que, para cumplir con su cometido, el derecho penal se vale de normas que incluyen una serie de elementos y que, a su vez, cumplen con unas funciones que demuestran su legitimidad y necesidad dentro de la política criminal de un Estado. En términos generales, la normal penal tiene un precepto y una sanción. Por el primero, se entiende la descripción taxativa del comportamiento que resulta repudiable y al que se le considera delito; es la acción u omisión prohibida objeto de sanción. La sanción por su parte, es la pena que acarrea el delito y que, implica un juicio de reproche. De estos elementos se puede observar que, la norma penal no se libra el azar, ni es producto de los caprichos del legislador. Ella, "es el fruto de un raciocinio basado en circunstancias que dan origen a la inclusión de determinada conducta como delito y que, además, cumple una función" (Zugaldia, 1993, pp. 55). Es decir, se trata de una fuente material.

Dentro de las funciones que cumple la norma penal, se pueden señalar tres. La primera, una función valorativa que se traduce en que la norma penal se somete objetivamente a una "estimación de valor negativo, producto de la conducta que ella considere indeseada por afectar bienes jurídicos de vital importancia. Se hace referencia aquí, de una valoración negativa que tiene en cuenta el daño merecedor de la pena criminal”. (Fernández, 2011 a, p. 227).

La segunda una función motivadora que, se dirige a los destinatarios de la norma penal con "capacidad de orientarse a la comprensión de la misma. Es decir, de adecuar su comportamiento a los que la norma prohíbe, para lo cual, el destinatario ha de internalizarla y aceptarla para así dirigir su conducta al querer del legislador". (Fernández, 2011 a, p. 229). Por último, la norma cumple una función protectora que, se traduce, en "lo que busca la norma preservar a través de las prohibiciones que ella crea. En resumidas cuentas, ello es, un bien jurídico”. (Muñoz, 2001a, p.93).

\section{Origen y concepto del bien jurídico}

"La teoría del bien jurídico aparece en el siglo XIX con una motivación liberal y con la visible intención de limitar la obra del legislador penal" (Antolisei, 1939, p. 3), describe el "catálogo de hechos susceptibles de pena únicamente a lo socialmente dañoso" (Stella, 1973, p. 4). "Este concepto fue acuñado por J.M.F Birnbaum en 1834 y, se le ha identificado como "derecho subjetivo, ligado a la idea de interés vital". (Álvarez, 1991, p. 5). En otros términos, "el bien jurídico puede ser entendido como la base necesaria que requieren las personas para su autorrealización en la vida social" (Muñoz, 2001, p. 91) o, como el "punto de partida y la idea que preside la formación del tipo, 
cuyo objetivo es lograr mantener custodiados intereses supremos" (Hans, 1981, p. 350). El bien jurídico, no se refiere a cualquier bien; como bien apunta Fernández Carrasquilla (2011), "se trata de un bien del derecho justo, necesario por el desenvolvimiento de la sociedad y de los individuos que en ella coexisten". (p. 296).

El bien jurídico se denomina de formas diversas, tales como: "derecho protegido, bien garantizado, interés jurídicamente tutelado, objeto jurídico" (Pisapia, 1965, p.43). Asimismo, algunos autores identifican el bien jurídico tutelado como "todo valor de la vida humana protegida por el derecho" (Cobo, 1988, p. 249). No es otra cosa que, el querer del legislador de darle protección a ciertos valores del ser humano o de la sociedad, y que se conviertan en intereses generales dentro del Estado, pero que, a su vez, dichos bienes jurídicos han de ser protegidos y definidos no únicamente por el contexto social que requiere de intervención del legislador a fin de evitar daños al individuo, sino, por los compromisos adquiridos en virtud de normas supranacionales. En otros términos, es definir el bien objeto de protección desde la esfera del contexto social, sin desligarse de las normas del derecho internacional de los Derechos Humanos que, para ciertas prohibiciones, han determinado bienes jurídicos.

\section{Bienes jurídicos protegidos en Latinoamérica con la prohibición del delito de tortura}

De lo expuesto anteriormente, se ha afirmado que la normatividad internacional para la prohibición de la práctica de la tortura ha establecido un bien jurídico tutelado, el cual es, la integridad personal. Sin embargo, se ha observado que los códigos penales de la región que fueron abordados en este estudio, difieren abiertamente de dicho bien jurídico. Asimismo, se nota que existe una posición mayoritaria en considerar que con la prohibición del delito de tortura debe ampararse la libertad individual. Ejemplo de estos códigos penales son los de: Colombia, Argentina, Bolivia, Guatemala y Honduras, entre otros.

Otros códigos sugieren que con la prohibición de la tortura debe ampararse a la humanidad. Ejemplo de estos países son: Perú y Uruguay. A su vez, países como Costa Rica y República Dominicana -Protege a particulares ligándolo a la integridad personal-, sugieren que el bien jurídico a tutelar con la prohibición de la tortura es la integridad personal. En Chile, la Integridad moral; en el Salvador los derechos y garantías fundamentales de las personas; en Nicaragua el orden internacional; en Paraguay, las funciones del Estado; otros países no tienen tipificado aun el delito o por lo menos, lo tienen subsumido a otra conducta. Para determinar el bien jurídico adecuado a tutelar, con la prohibición del delito de tortura en la perspectiva penal latinoamericana, se partirá por estudiar los distintos bienes jurídicos que nos ofrecen los códigos penales de los países abordados, para así pronunciarse al respecto.

\section{Libertad personal}

Frente a la posición mayoritaria de países que, con la prohibición de la tortura amparan el derecho a la libertad personal. En este trabajo se disiente respetuosamente de tal posición. Para ello, se hará las precisiones al respecto. La libertad personal es la facultad 
que tiene toda persona humana al desarrollo de su potestad personal, es decir, al desarrollo de sus potencialidades como individuo para el cumplimiento de su proyecto vital. Es un "principio y derecho fundante que comprende, la posibilidad y el ejercicio positivo de todas las acciones dirigidas a desarrollar las aptitudes y elecciones individuales que no pugnen con los derechos de los demás, ni entrañen abuso de los propios". (CCCO, 2001c). Se trata de un derecho subjetivo, que "abarca todas las manifestaciones de la libertad constitucionalmente protegibles, no específicamente protegidas por derechos fundamentales autónomos". (Cámara, 2012, p. 8). Al igual que los demás derechos, es susceptible de limitación, razón por la cual, toda interferencia que se haga sobre el mismo debe ajustarse a lo contemplado en los convenios internacionales y en la ley.

Este derecho, se encuentra establecido en múltiples instrumentos del Derecho Internacional de los Derechos Humanos. De él, hace mención la Declaración Universal de los Derechos Humanos en su artículo 3, el Pacto Internacional de Derechos Civiles y Políticos en su artículo 9, la Declaración Americana de Derechos y Deberes del Hombre en su artículo 1, la Convención Americana sobre Derechos Humanos en su artículo 7, el Convenio Europeo de Derechos Humanos y Libertades Fundamentales en su artículo 5 y la Carta de Banjul en su artículo 6.

De los mencionados instrumentos, se desprenden una serie de garantías especificas en cuanto a este derecho, tales como: 1) la prohibición de detenciones o encarcelamientos ilegales y arbitrarios (Corte IDH, 2012p); 2) el deber de informársele a una persona, las razones de su detención y a recibir notificación oportuna de los cargos que se le formulan (Corte IDH, 2008q); 3) la facultad de ser llevado, sin demora, ante un juez u otro funcionario autorizado por la ley para ejercer funciones judiciales (Corte IDH, 2008r); 4) la facultad de ser juzgado dentro de un plazo razonable; 5) el derecho de recurrir ante un juez o tribunal competente, a fin de que se decida, sin demora, sobre la legalidad del arresto o de la detención y a que se ordene la libertad si el arresto o la detención fueran ilegales (Corte IDH, 2008s); 6) la prohibición de ser detenido por deudas y, 7) el derecho a contar con asistencia consular, en el caso de extranjeros detenidos en el país receptor (Convención de Viena sobre Relaciones Consulares [GVRG], 1967).

Dichas garantías específicas, "han permitido establecer un consenso en el sentido de que el contenido esencial de este derecho, es la protección de la libertad del individuo" (O’Donnel, 2004, p. 280) contra la "interferencia arbitraria o ilegal del Estado" (CDH, 1982b), y a su vez, la "garantía del Derecho de defensa del detenido" (Corte IDH, $2012 \mathrm{t}$ ).

En referencia a este derecho, y la prohibición de la tortura, se concuerda en este trabajo por lo sostenido por el Comité de Derechos Humanos de Naciones Unidas (CDH, 2001c), el cual, ha señalado que para aquellos que han sido privados de su libertad, el artículo 10 del Pacto es quien complementa la prohibición de tortura y no, el artículo 7 del mismo. Según el Comité, las personas privadas de libertad, gozan del derecho positivo de ser tratados con respeto. Esta disposición implica que, los detenidos no pueden ser sometidos a 
penurias o a limitaciones que no sean las que resulten de la privación de la libertad; razón por la cual, debe garantizarse el respeto de la dignidad a los privados de la libertad en las mismas condiciones que a las personas libres (CDH, 1992d).

Asimismo, del análisis de la jurisprudencia citada (CDH, 1992d) se observa que, comúnmente se aplica a las condiciones generales de detención, el artículo 10.1 del Pacto y, se reserva, la aplicación del artículo 7 del mismo para aquellas situaciones en las que un individuo sufre ataques específicos a su integridad personal. Ejemplo de ello, es que en el caso Kennedy Vs. Trinidad y Tobago, el Comité estimó que:

Las golpizas a las que fue sometida la víctima por parte de la policía, mientras se encontraba privada de libertad, constituían una violación del artículo 7 del Pacto-integridad personal-; mientras que las condiciones generales en las que se encontraba detenido, que incluían hacinamiento durante la etapa de prisión preventiva y la incomunicación coactiva, violaban el artículo $10.1 \mathrm{del}$ mismo (CDH, 2002e).

Seguidamente, en su Observación General No. 35 aprobada en su $107^{\circ}$ periodo de sesiones de 2013, el Comité (CDH, 2014f), haciendo una interpretación del derecho a la libertad y seguridad personal establece que:

El derecho a la seguridad personal es independiente del derecho a la libertad personal y, protege a las personas de no ser lesionados en el cuerpo o en la integridad personal, estén éstas o no privadas de su libertad por parte de la autoridad pública. En esa misma oportunidad, el Comité insiste, tal y como lo hizo en su observación general No. 7 y en la observación general No. 20 que, el Pacto Internacional de Derechos Civiles y Políticos, protege a las personas de no ser objetos de tortura, entendiendo por esta última, una conducta que afecta la integridad personal.

Por lo expuesto, se disiente con los códigos penales que sugieren tutelar el derecho a la libertad personal con la prohibición de la tortura. Ello, toda vez que se podría concluir de forma errónea, que una persona que no se encuentre privada de su libertad no pueda ser objeto de esta práctica aberrante; estableciéndose así, un límite inapropiado para esta forma de conducta. Máxime, cuando ni la normatividad internacional ni la jurisprudencia hasta ahora existente, en la materia, condicionan la procedibilidad de la tortura previa privación de la libertad.

\section{Crímenes contra la humanidad o DE LESA HUMANIDAD}

En la actualidad, dos códigos penales latinoamericanos consideran que, con la prohibición de la tortura, se tutelan los crímenes contra la humanidad o de lesa humanidad. Estos son a saber: el código penal de la República del Perú y, el código penal de la República de Uruguay. Como bien es sabido, por el término crimen de lesa humanidad, se puede hacer referencia a aquellos actos delictivos que, por su naturaleza monstruosa, ofenden o injurian a toda la raza humana en su conjunto (Rueda, 2001). Sobre este tipo de crimen, se hace referencia en la Carta de Londres de 1945, en la cual, se establecieron las reglas que se observarían 
en los juicios de Núremberg. En su contenido material, la Carta dispuso que el Tribunal de Núremberg fuera competente para conocer de los crímenes de guerra, contra la humanidad y contra la paz.

Respecto de los crímenes contra la humanidad, se encuentra una muy limitada definición en el Estatuto del Tribunal Militar Internacional de Núremberg, en su artículo 6.C que los define así: el asesinato, la exterminación, esclavización, deportación y otros actos inhumanos cometidos contra población civil antes de la guerra o durante la misma; la persecución por motivos políticos, raciales o religiosos en ejecución de aquellos crímenes que sean competencia del Tribunal o en relación con los mismos, constituyan o no una vulneración de la legislación interna del país donde se perpetraron.

Una definición sobreviniente a la anterior, se vislumbró con el Estatuto del Tribunal Penal Internacional para la Ex Yugoslavia, el cual estableció en su artículo 5 que eran crímenes de lesa humanidad: 1) Asesinato; 2) Exterminio; 3) Esclavitud; 4) Deportación; 5) Encarcelamiento; 6) Tortura; 7) Violación; 8) Persecución por motivos políticos, raciales o religiosos y, 9) Otros actos inhumanos. Sin embargo, para ser considerados crímenes de lesa humanidad, existía la condición que debían haber sido cometidos contra la población civil durante un conflicto armado, interno o internacional. Cuestión que supondría, una remisión directa a las normas del derecho internacional humanitario y que, en últimas, podría habérseles confundido con los crímenes de guerra.

Por su parte, el Estatuto del Tribunal Internacional para Ruanda, en su artículo 3, establece como crimen de lesa humanidad, aquellos que hayan sido cometidos en el curso de un ataque generalizado y sistemático, y dirigidos contra cualquier población civil en razón de su nacionalidad o pertenencia a un grupo político, étnico, racial o religioso. Cabe resaltar que, este Estatuto también incluye como delitos de lesa humanidad, los que contempló el Estatuto del Tribunal Internacional para la EX Yugoslavia.

En cuanto a este punto y, observando que tanto la República del Perú como la Republica del Uruguay, son Estados partes en el Estatuto de Roma de la Corte Penal Internacional, se considera necesario observar los requisitos que consagra el mencionado Estatuto, para que se configure un crimen de lesa humanidad. Respecto a ello, el Estatuto hace referencia a tres requisitos: 1) que se cometa un ataque generalizado o sistemático, 2) que el ataque se cometa contra la población civil y, 3) que exista conocimiento del ataque, es decir, de su entidad por quien lo ejecuta.

Atendiendo a lo expuesto, podemos afirmar que proteger con la prohibición de la tortura a la humanidad, de los crímenes que más la afecten a esta, es limitable de cualquier forma de tortura en estos países. La razón es sencilla, toda vez que, por un lado, la definición de crimen de lesa humanidad es propia del derecho internacional y no del derecho constitucional o nacional y, en los eventos en los cuales un determinado Estado pretenda definirlos, no puede hacerlo en contravía de instrumentos internacionales en detrimento de principios como el del pacta sunt servanda; por el otro, se descartaría toda comisión del delito de tortura, originado por fuera de los ataques generalizados o sistemáticos contra 
la población civil y, con conocimiento de dicho ataque. En otras palabras, no existiría la posibilidad de poder hablar de la tortura ocurrida con ocasión de hechos aislados, cuestión última que generaría la impunidad frente a este tipo de situaciones.

\section{INTEGRIDAD PERSONAL, INTEGRIDAD MORAL, DEREGHOS Y GARANTÍAS DE LAS PERSONAS}

Se decidió unir estos tres diferentes bienes jurídicos bajo un mismo análisis, dado que, corresponden a los tutelables con la prohibición del delito de tortura en Costa Rica, República Dominicana, Chile y el Salvador. El motivo de hacer este estudio conjunto, es por la estrecha relación que existe entre la integridad personal y la integridad moral, la cual se encuentra subsumida en la primera, pero que, ambas, se encuentran insertas en los derechos y garantías de las personas.

El derecho a la integridad personal, es un derecho innato al igual como acontece con los demás Derechos Humanos que se les reconocen a las personas. Con él, se busca el respeto y garantía de la integridad física, psíquica y moral, prohibiendo con ello, la injerencia arbitraria del Estado y de los particulares en esos atributos individuales. Este derecho implica un sentido positivo derecho a gozar de integridad fisica, psicológica y moral, y un sentido negativo (CCCO, 1998d) el cual es el deber de no maltratar, no ofender, no torturar y no comprometer o agredir la integridad física y moral de las personas (TEDH, 1995g).

De conformidad con el contenido de este derecho en el Pacto de San José, así como en el Pacto Internacional de Derechos Civiles y Políticos, la integridad personal implica en consecuencia, el conjunto de condiciones que permiten que una persona pueda gozar de su vida, con plenitud de las funciones orgánicas, psíquicas y morales (Corte IDH, 2006). En el aspecto físico, la integridad personal hace referencia a la conservación del cuerpo humano en su forma anatómica y al equilibrio funcional y fisiológico de los diferentes órganos que lo integran. Este derecho protege la integridad física de las personas de ataques injustos contra el cuerpo o la salud, que produzcan incapacidad para trabajar o para desplazarse, o que le causen enfermedad, deformaciones físicas o mutilación a cualquiera de sus miembros (Pérez, 1991).

En lo concerniente al ámbito psicológico del ser humano, la integridad personal busca garantizar al individuo las plenas facultades mentales propias de su actividad cerebral, tales como la razón, la memoria, el entendimiento, la voluntad etc. El normal funcionamiento físico y psíquico de una persona asegura un despliegue de sus facultades humanas de una manera completa (Defensoría del Pueblo de Colombia, 2001, p. 18). En el aspecto moral, la integridad se refiere a la autonomía del individuo para mantener, cambiar y desarrollar sus valores personales. Cualquier tipo de atentado que "humille y agreda moralmente a una persona, como los insultos, la trata de personas, la prostitución o las violaciones carnales, puede comprometer no solo la dimensión física y psicológica de un individuo, sino también la dimensión moral del mismo" (Reyes, 2001, p. 17).

Por su contenido, muchos instrumentos internacionales colocan a este derecho en el 
núcleo inderogable de derechos que, no puede ser suspendido en casos de guerras, de peligro público o de otra emergencia que amenace la independencia, o seguridad de un Estado. Respecto al derecho a la integridad personal y la prohibición de la tortura, los instrumentos internacionales de Derechos Humanos colocan a ésta, como una de las prohibiciones que afectan la integridad personal. Es decir, dentro del contenido de este derecho, se inserta la prohibición de la tortura y otros tratos o penas crueles inhumanos o degradantes, con el fin de que los Estados se comprometan a no torturar y, a garantizar que ni sus agentes ni los particulares afectaran este derecho. La jurisprudencia de la Corte Interamericana de Derechos Humanos (2012p; TEDH, 1995g), ha remarcado con especial énfasis que toda conducta constitutiva de tortura es violatoria del derecho a la integridad personal.

Por lo anterior, en este trabajo se comparte la idea de que, con la prohibición de la tortura, se ampara el derecho a la integridad personal en todas sus vertientes. Posición que, a nuestra vista, refleja una postura más garantista, al no exigir o requerir un condicionante previo para que pueda afectarse la integridad personal. Es decir, según los instrumentos de Derechos Humanos y la jurisprudencia citada, no es necesario que una persona se encuentre privada de su libertad para ser objeto de tortura, así como tampoco es requerido de que se deba cometerse el delito de manera sistemática o generalizada en contra de la población civil, ni con afectación a las funciones del Estado.

\section{Conclusiones}

La tortura es un flagelo cuyos orígenes se remontan al comienzo de la historia de la humanidad. Ella, ha estado presente en todas las culturas que se han destacado por los logros que han alcanzado. En sus inicios, la tortura fue una pena que se derivaba de las conductas que, para los gobernantes eran una máxima ofensa; luego fue empleada con el fin de cumplir las exigencias de la iglesia y así lograr purgar los pecados. Con el advenimiento de la edad moderna, se observa uno de los más grandes cambios que permearon muchas instituciones y, resaltaron el valor del ser humano en la atención a su dignidad. Fruto de lo anterior, fue que en la edad contemporánea la tortura o penas crueles inhumanos o degradantes fuesen proscritas en todas sus vertientes.

Como garantía de dicha proscripción, se crearon una serie de instrumentos internacionales que garantizan la eliminación del flagelo de la tortura para toda la humanidad; instrumentos estos que, en su mayoría, forman parte del bloque de constitucionalidad de muchos Estados y, los cuales a su vez, exigen la aplicación de un control de convencionalidad. Los instrumentos de Derechos Humanos que prohíben la tortura, tutelan con esta prohibición el derecho a la integridad personal, toda vez que este protege al individuo en una dimensión física, psíquica y moral.

Razón por la cual, tutelar un derecho diferente con esta prohibición, impediría la persecución de este delito en la jurisdicción del Estado al no poderse demostrar la afectación del bien jurídico exigido por el legislador y, se haría imposible la investigación, 
enjuiciamiento y castigo efectivo frente a este delito. Asimismo, ello generaría limitaciones el cumplimiento de los tratados internacionales de conformidad con el deber de adoptar disposiciones de derecho interno.

\section{REFERENGIAS}

Alain Pellet y Patrick Daillier. (1999). Droit International Public, París, Edit. LGDJ.

Álvarez García, F. J. (1991). "Bien jurídico y Constitución”. Cuadernos de política criminal. No. 43.

Antolisei, F. (1939). Il problema del bene giurídico. En Rivista Italiana di Diritto Penale, Edit. Giuffre, Milano.

Cámara Arroyo, S. (2012). Libertad personal. Publicado en el diccionario de Derechos Humanos de la Universidad Alcalá de Henares, Madrid, 2012, pág. 8. disponible en: http://diccionario.pradpi.org/inicio/ index.php/terminos_pub/to_pdf/21.

Cervini, R. (2016). Derecho penal econômico. Concepto y bien jurídico. Instituto de Derecho Penal, (1).

Cobo del Rosal, M. y Vives, A. (1988). Derecho penal. Parte general, Edit. Tirant lo Blanch, Madrid, España.

Comisión de Derechos Humanos. (1995). Cuestión de los Derechos Humanos de todas las personas sometidas a cualquier forma de detención o prisión, y en particular la tortura y otros tratos o penas crueles, inhumanos o degradantes. Informe del Relator Especial, Sr. Nigel S. Rodley, presentado con arreglo a la resolución 1992/32 de la Comisión de Derechos Humanos.

Comisión Interamericana De Derechos Humanos. (1981b). Informe sobre los Derechos Humanos en Colombia, OEA/Ser.L/V/ II.53. doc.22.
Comisión Interamericana De Derechos Humanos. (2001a). Informe No. 53/01, caso 11.565 de Ana, Beatriz y Cecilia Gonzales Pérez vs México.

Comité Contra La Tortura. (2007c). Caso V.L vs. Suiza.

Comité Contra La Tortura. (2008a). Observación General No. 2.

Comité Contra La Tortura. (2008b).

Observaciones Finales del $43^{\circ}$ periodo de sesiones respecto de ARZEBAIJAN.

Comité de Derechos Humanos (2001c), Observación General No 29. UN Doc. HRI/ GEN/1/Rev.7. G

Comité de Derechos Humanos. (1982b).

Observación general No. 8. U.N. Doc. HRI/ GEN/1/Rev.7

Comité de Derechos Humanos. (1983a). Caso.

Miguel Angel Estrella vs. Uruguay

Comité de Derechos Humanos. (1992d). Observación General No 21. UN Doc. RI/ GEN/1/Rev.7.

Comité de Derechos Humanos. (2002e).

Case of Kennedy c. Trinidad y Tobago,

Comunicación Nº 845/1998.

Comité de Derechos Humanos. (2014f).

Observación General No. 35. UN DOC.

CGPR/C/107/R.3.F

Convención de Viena sobre Relaciones

Consulares. (1967).

Corte Constitucional De Colombia. (1992a).

Sentencia C-587.

Corte Constitucional de Colombia. (1998d).

Sentencia T-427.

Corte Constitucional de Colombia. (2001c)

Sentencia C - 774.

Corte Constitucional De Colombia. (2002b)

Sentencia C-1076. 
Corte Interamericana de Derechos Humanos. (1997h). Caso Loayza Tamayo vs Perú. Fondo.

Corte Interamericana de Derechos Humanos. (2003o). Caso Maritza Urrutia vs Guatemala. Fondo.

Corte Interamericana de Derechos Humanos. (2004m). Caso de los Hermanos Gómez Paquiyauri vs Perú. Fondo.

Corte Interamericana de Derechos Humanos. (2004n). Caso Tibi vs Ecuador. Fondo.

Corte Interamericana de Derechos Humanos. (2006b). Caso del Penal Miguel Castro Castro Vs. Perú. Fondo.

Corte Interamericana de Derechos Humanos. (2006f). Caso Baldeón García Vs. Perú. Fondo.

Corte Interamericana de Derechos Humanos. (2006u). Caso La Cantuta Vs. Perú. Fondo.

Corte Interamericana de Derechos Humanos. (2008q). Caso Tiu Tojín Vs. Guatemala. Fondo.

Corte Interamericana de Derechos Humanos. (2008r). Caso Bayarri Vs. Argentina. Fondo.

Corte Interamericana de Derechos Humanos. (2008s). Caso Yvon Neptune Vs. Haití. Fondo.

Corte Interamericana de Derechos Humanos. (2011c). Caso Rosendo Cantú y otra Vs. México. Interpretación de la Sentencia de Excepción Preliminar, Fondo, Reparaciones y Costas.

Corte Interamericana de Derechos Humanos. (2011k). Caso Contreras y otros Vs. El Salvador. Fondo.

Corte Interamericana de Derechos Humanos. (20111). Caso Fleury y otros Vs. Haití. Fondo.

Corte Interamericana de Derechos Humanos. (2012p). Caso Uzcátegui y otros Vs. Venezuela. Fondo.
Corte Interamericana de Derechos Humanos. (2012t). Caso Gudiel Álvarez y otros Vs. Guatemala. Fondo.

Corte Interamericana de Derechos Humanos. (2014a). Caso Espinoza Gonzáles Vs. Perú. Fondo.

Corte Interamericana de Derechos Humanos. (2015e). Caso Ruano Torres y otros Vs. El Salvador. Fondo.

Corte Interamericana de Derechos Humanos. (2015g). Caso Quispialaya Vilcapoma Vs. Perú. Fondo.

Corte Interamericana de Derechos Humanos. (2016d). Caso Herrera Espinoza y otros Vs. Ecuador. Fondo.

Corte Interamericana de Derechos Humanos. (2016i). Caso Pollo Rivera y otros Vs. Perú. Fondo.

Corte Interamericana de Derechos Humanos. (2016j). Caso Tenorio Roca y otros Vs. Perú. Fondo.

Defensoría del Pueblo de Colombia. (2001). Derecho a la integridad, Bogotá, Colombia.

Díez de Velasco, M. (1999). Instituciones de Derecho Internacional Público, Madrid, Españat, Tecnos.

Fernández Carrasquilla, J. (2011). Derecho penal parte general: principios y categorías dogmáticas, Bogotá, Ed. Ibañez.

Jescheck Hans, H. (1981). Tratado de derecho penal, parte general. Traducción y adiciones de derecho penal español por Santiago Mir Puig y Francisco Muñoz Conde. (1), Bosch, Barcelona.

Jiménez de Asúa, L. (1950) Tratado de derecho penal, Tomo II. Filosofía y ley penal, Buenos Aires, editorial Losada S.A.

Muñoz Conde, F. (2001). Introducción al derecho penal, buenos aires, Argentina. Euro Editores, $2^{\circ} \mathrm{Ed}$. 
O`donnel, D. (2004). Derecho Internacional de los Derechos Humanos, Normativa, Jurisprudencia y Doctrina de los sistemas Universal e Interamericano, Bogotá, Colombia. Ed. Tierra Firme.

Pérez, L. (1991). Derecho Penal. Bogotá, Colombia. Ed Temis.

Pisapia, G. D. (1965). Instituzioni di Diritto Penale. Parte Generale e Parte Speciale, Padova.

Requena, I. G. Amuchategui y Díaz, I. (2015). Derecho penal. Banco de preguntas. Oxford University Press.

Reyes, A. (2001). Derecho a la integridad. Bogotá, Colombia.

Rueda Fernández, C. (2001). Delitos de derecho internacional: tipificación y represión internacional. Madrid, España. Ed. Bosch.

Sánchez, B. F. (2016). Sobre el contenido y la evolución del Derecho Penal español tras la LO 5/2000 y la LO 7/2000. En Jurídica Universidad Autónoma de Madrid.

Stella, F. (1973). La teoría del bene giurídico. Fatti inoffensivi conformi al tipo. En Rivista Italiana di Diritto e Procedura penale, Milano.

Tribunal Europeo de Derechos Humanos. (1982h) Case of Campbell and Cosans. Judgment.

Tribunal Europeo de Derechos Humanos. (1989i). Case of Soering v. United Kingdom, Judgment.

Tribunal Europeo de Derechos Humanos. (1992f). Case of Tomasi v. France, Judgment.

Tribunal Europeo de Derechos Humanos. (1995g). Case of Ribitsch v. Austria, Judgment.

Tribunal Europeo de Derechos Humanos. (1996e). Case of Chahal v. United Kingdom, Judgment.

Tribunal Europeo de Derechos Humanos. (1997j). Case of Aydin v. Turkey (GG), Judgment.
Tribunal Europeo de Derechos Humanos. (1999d). Case of Selmouni v. France, Judgment.

Tribunal Europeo de Derechos Humanos. (2000c). Case of Labita v. Italy, Judgment.

Tribunal Europeo de Derechos Humanos. (2004a). Case of M.C vs. Bulgaria. Judgment.

Tribunal Europeo de Derechos Humanos. (2008b). Case of Chitayev \& Chitayev vs. Rusia. Judgment.

Tribunal Penal Internacional para la Antigua Yugoslavia. (1998). Case of Prosecutor v. Anto Furudzija.

Zugaldia Espinar, J. M. (1993). Fundamentos del derecho penal, Valencia, España. 